\title{
Tensile Characterizations of Oil Palm Empty Fruit Bunch (OPEFB) Fibres Reinforced Composites in Various Epoxy/Fibre Fractions
}

\author{
Mohd Khairul Faizi ${ }^{1}{ }^{\mathbb{D}}$, Shahriman Abu Bakar ${ }^{1 \mathbb{D}}$, Mohd Shukry Abdul Majid ${ }^{1}{ }^{\mathbb{D}}$, Shamsul Bahri Mohd \\ Tamrin 2(D), Haris Ahmad Israr 3**(D), Anas Abdul Rahman 1(D), Ng Yee Guan 2(D), Zuradzman Mohd \\ Razlan 1(D), Norzarul Asri Kamis 1(D), Wan Khairunizam ${ }^{1(D)}$
}

1 Faculty of Mechanical Engineering Technology, Universiti Malaysia Perlis, Pauh Putra Campus, 02600 Arau, Perlis, Malaysia; mkhairulfaizi@unimap.edu.my (M.K.F), shahriman@unimap.edu.my (S.A.B), shukry@unimap.edu.my (M.S.A.M), anasrahman@unimap.edu.my (A.R), zuradzman@unimap.edu.my (Z.M.R), norzarul@unimap.edu.my (N.A.K), khairunizam@unimap.edu.my (W.K.W);

2 Faculty of Medicine and Health Science, Universiti Putra Malaysia, 43400 UPM Serdang, Selangor, Malaysia; shamsul_bahri@upm.edu.my (S.B.M.T), shah86zam@upm.edu.my (N.Y.G);

3 School of Mechanical Engineering, Faculty of Engineering, Universiti Teknologi Malaysia, 81310 Johor Bahru, Johor, Malaysia; harisahmad@utm.my (H.A.I);

* Correspondence: harisahmad@utm.my (H.A.I);

Scopus Author ID 55425727000

Received: 3.07.2021; Revised: 10.09.2021; Accepted: 14.09.2021; Published: 8.11.2021

\begin{abstract}
Oil palm empty fruit bunch (OPEFB) single fibers and reinforced composites were comprehensively characterized through tensile tests to assess their performance as potential reinforcing materials in polymer composites. The performances of OPEFB single fibers and reinforced composites with untreated and treated fibers conditions were compared. The fibers were variously treated with $3 \%$ sodium hydroxide, $2 \%$ silane, $3 \%$ sodium hydroxide mixed with $2 \%$ silane, and $3 \%$ sodium hydroxide prior to $2 \%$ silane for 2 hours soaking time. The highest toughness of the single fibers test was then selected to proceed with composites fabrication. The OPEFB composites were fabricated in 90:10, 80:20, 70:30, and 60:40 epoxy-fibre fractions. The result shows that the selected treated fiber composite exhibits better performance. The selected treated fiber composite increased the highest ultimate tensile strength by $145.3 \%$ for the $90: 10$ fraction. The highest Young's Modulus was increased by about $166.7 \%$ for $70: 30$ fraction. Next, the highest toughness was increased by $389.5 \%$ for the $30: 70$ fraction. The treated fibers provided a better interlocking mechanism between the matrix and fibers in reinforced composites, thus improving their interfacial bonding.
\end{abstract}

Keywords: natural fiber; oil palm empty fruit bunch fibers; alkaline treatment; tensile properties; volume fraction.

(C) 2021 by the authors. This article is an open-access article distributed under the terms and conditions of the Creative Commons Attribution (CC BY) license (https://creativecommons.org/licenses/by/4.0/).

\section{Introduction}

There has been an escalating interest in finding alternative fibers for effective and inexpensive energy-absorbing composites in recent years. Among the available possibilities is to use natural fiber to produce polymer composite since it is eco-friendly, abundant, and renewable naturally. In addition, natural fibers offer many advantages, for example, affordability, biodegradability, low density with acceptable specific properties, good insulating and thermal properties, low energy consumption during processing, etc. [1-4]. At present, among the natural fibers that are frequently investigated to form polymer composites are flax, 
jute, cotton, kenaf, hemp, and basalt. These natural fibers are usually applied with polymer matrices, i.e., epoxy and polyester, to provide better specific tensile and flexural properties, stiffness, and elongation at break [5-15]. Examples of widely employed matrices include thermoplastic polymer: polypropylene (PP); polyvinyl chloride (PVC); polyethylene (PE); and polystyrene (PS), thermosets polymers: phenolics; epoxies; isocyanates, and unsaturated polyesters.

The oil palm empty fruit bunch (OPEFB) is a promising natural fiber to be explored [16]. OPEFB is categorized as an oil palm industry biomass waste that is generated from the oil extraction mills process. Literature-wise, plenty of studies have been conducted to make OPEFB polymer composite characteristics even better [1,3,7-11]. Nevertheless, the effect of volume fractions between the OPEFB fiber and matrix as well as the effect of alkaline treatment has not been sufficiently investigated.

Malaysia is among the most important oil palm producers in the world and experiencing a robust development in new oil palm plantations and palm oil mills through giant governmentlinked companies (e.g., FELDA, FELCRA, SALCRA, SLDB, KESEDAR, PKEINK, and RISDA) and private estates (e.g., Guthrie, IOI Plantations, Genting Plantations, and Sime Darby). The total area of oil palm cultivations in 2018 is about 5.85 million hectares, in which the bigger percentage are from private estates contribution at 71.6\% [8-15].

In the oil palm industry, the existing biomass wastes are generated by two processes [33]. The first is from plantation routines involving pruning and re-plantation, where it generates wastes such as fronds and trunks, whereas the second is from the oil extraction mills where wastes such as oil palm empty fruit bunch (OPEFB) and mesocarp fiber are produced.

As the oil palm industry becomes bigger and wider in Malaysia, many oil palm leftovers are produced, causing an excess of waste products. After the palm oil extraction process, the waste by-product could exceed 80 million tons per annum [34]. This problem tends to burden the operators with disposal difficulties and escalates the operating cost. In addition, these wastes contribute to environmental problems because most of the OPEFB were burned in the open [5,18]. Furthermore, the production of OPEFB in the last 20 years has shown an apparent increasing trend from 2.8 - 3 million tones in the year 1997 [1], 7 million tons in 2009 [33], 22.43 million tons in 2016 [34], and approximately 24.66 million tons in 2018.

Hence, an effort has been made in the present work to investigate the mechanical characterizations of OPEFB fibers reinforced composites in various epoxy-fiber fractions with and without alkaline treatment. The purpose of this study is to explore the potential of the OPEFB fiber composite to be converted into some forms of beneficial products. The composite is fabricated by a hand lay-up technique to characterize the tensile mechanical behaviors.

\section{Materials and Methods}

\subsection{Preparation of OPEFB fibers.}

The United Oil Palm Industries, Nibong Tebal, Penang, had supplied the OPEFB for this research works. Following the water retting process, the fibers were manually extracted. The water retting took about a week to remove the residual oil and cleaned using distilled water. Next, the fibers were dried under the sun to ensure the removal of their moisture content. The extracted fibers are shown in Figure 1. 


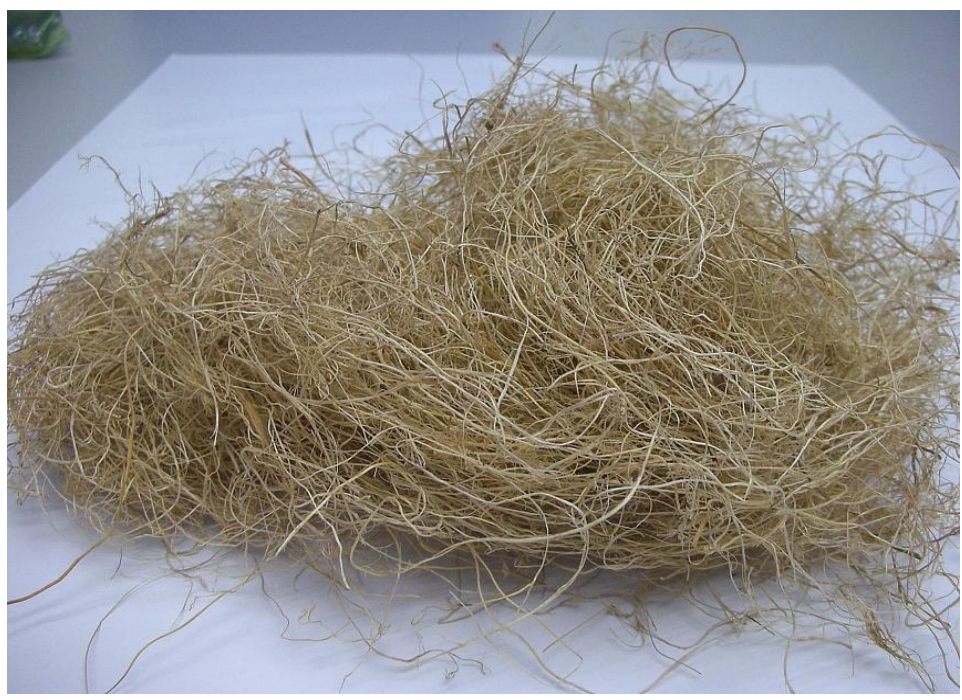

Figure 1. The extracted OPEFB fibers.

\subsection{Chemical treatment of $O P E F B$ fibers.}

The OPEFB fibers were treated with four different methods of alkaline treatments: $\mathrm{NaOH}(3 \%)$, silane (2\%), mixed $\mathrm{NaOH}(3 \%)+$ silane (2\%), and multistage $\mathrm{NaOH}(3 \%)$ - silane $(2 \%)$. All the treatments were soaked for about two hours at room temperature, and the liquor ratio was maintained at 40:1. Finally, the fibers were cleaned using distilled water and subsequently dried at room temperature.

\subsection{Preparation of composites.}

The epoxy resin used in this research is EpoxAmite 100 and 103 with slow hardeners as a curing agent. The extracted natural fibers were subsequently compressed using a cold press, and the hand-lay-up method was adopted to fill up the prepared mold with the appropriate amount of resin mixture that was evenly distributed. The lid was then placed on top of the fibers to help form the composite shape. The curing process was done at room temperature, which took approximately 24 hours.

\subsection{Tensile test.}

The single fiber tests were performed according to ASTM D3822-07 standard using the INSTRON micro tester. All single fiber tests were carried out at a rate of $0.5 \mathrm{~mm} / \mathrm{min}$ using a $10 \mathrm{~N}$ load cell. On the other hand, the tensile properties of the composite were determined through the tensile testing method in accordance with ASTM D3039 [36]. The tensile tests for the composites were carried out on a calibrated SHIMADZU testing machine at a rate of 1.00 $\mathrm{mm} / \mathrm{min}$ with a $250 \mathrm{kN}$ load cell.

\subsection{Surface morphology.}

The untreated and treated OPEFB fiber strands' surface morphology was examined using an SEM (HITACHI Model TM3000) with a magnification of 100X. The layers were not surface coated prior to scanning.

\section{Results and Discussion}

\subsection{Single fiber test.}


Single fiber properties are crucial to determine the efficiency of fibers and their quality. The stress-strain responses for the selected untreated and multiple treated OPEFB single fibers are presented in Figure 2. It can be seen that the treated fibers appear to have the tensile strength to be significantly increased and prolong the elongation at break in comparison to those of the untreated fibers. Moreover, the treated fibers have better ductility behaviors in contrast to the untreated fibers. Nevertheless, all the tested fibers are still considered brittle when observing the stress-strain responses as they experienced the sudden break upon reaching their ultimate tensile strength. From Figure 2, it can also be seen that the tensile strength of OPEFB fibers has been notably improved when treated by $\mathrm{NaOH}(3 \%)$ compared to other alkaline treatments. The ultimate tensile strength for the OPEFB fibers employed in this study is given in Figure 3, where the highest is for the $\mathrm{NaOH}(3 \%)$ treated at $82 \mathrm{MPa}$, followed by $\mathrm{NaOH}(3 \%)+$ silane $(2 \%)$, silane (2\%), $\mathrm{NaOH}(3 \%)$ - silane (2\%) and untreated fiber at $61.5 \mathrm{MPa}, 54.3 \mathrm{MPa}, 42.1$ $\mathrm{MPa}$, and $40 \mathrm{MPa}$ respectively. This corresponds to an improvement by about $105 \%, 53.8 \%$, $35.8 \%$ and $5.3 \%$ for the $\mathrm{NaOH}(3 \%), \mathrm{NaOH}(3 \%)+$ silane $(2 \%)$, silane $(2 \%)$ and $\mathrm{NaOH}(3 \%)$ - silane $(2 \%)$ treated fibres against the untreated specimen.

The previous study has also proven that the $3 \%$ of $\mathrm{NaOH}$ was the ideal concentration to optimally modify the strength of OPEFB fibers [37]. The critical surface modification done by the $\mathrm{NaOH}(3 \%)$ treatment is the disruption of hydrogen bonding in the fiber's structure, thus increasing the surface roughness. The $\mathrm{NaOH}(3 \%)$ treatment also changes the certain lignin and hemicellulose amount and removes wax and residue oils covering the external surface of the OPEFB fiber cell wall, similar to other typical natural fibers behavior as presented previously by other researchers [38]. Furthermore, previous experimental works based on the alkaline based treatment had reported that there were two major effects caused by this type of treatment on most of the natural fibers; better mechanical interlocking due to the increment of the surface roughness and the rises of the cellulose amount exposed to the surface of the fiber, which increases the number of possible reaction sites [39]. However, better interlocking due to the changes in surface roughness of OPEFB fibers does not improve the ductile behavior compared to the untreated. The change of cellulose fraction seems only likely to increase the strength but tended the strain slightly in close position compared to untreated. This indicates that the stronghold of the fibers due to better interlocking and the increases of cellulose amount could only be sustained in a short elongation and could not withstand the significant stroke during the tensile test.

Meanwhile, previous studies have suggested using $2 \%$ concentration as a benchmark for the silane treatment for natural fibers [40]. The silane treatment was used as a coupling agent to allow the glass fibers to adhere to a polymer matrix to stabilize the composite material. Recently, silane treatment was applied to the natural fibers to form stable covalent bonds on the cell wall chemisorbed onto the fiber surface, experiencing fiber swelling by creating a crosslinked network [41]. Apart from changing the cellulose, hemicellulose, and lignin fractions, the silane molecules also act as a surface coating on the fiber and react with the cellulose to form a strong chemical bonding with fiber constituents, as reported in [42]. Critically, past studies have shown that the natural fibers reactions on the silane treatment can cause the cellulose and hemicellulose to increase and couple together to establish a unique bonding [42]. However, the increase of cellulose and hemicellulose constituents of the OPEFB fibers is unable to significantly improve the ultimate tensile strength, in contrast to the $\mathrm{NaOH}$ (3\%) treatment. Nevertheless, the coating effects on the OPEFB fiber constituents have tremendously increased the strain. This shows that the coating effects from silane $(2 \%)$ 
treatment can remarkably prolong the elongation of the fibre, which in turn improving the ductility of the OPEFB fibres.

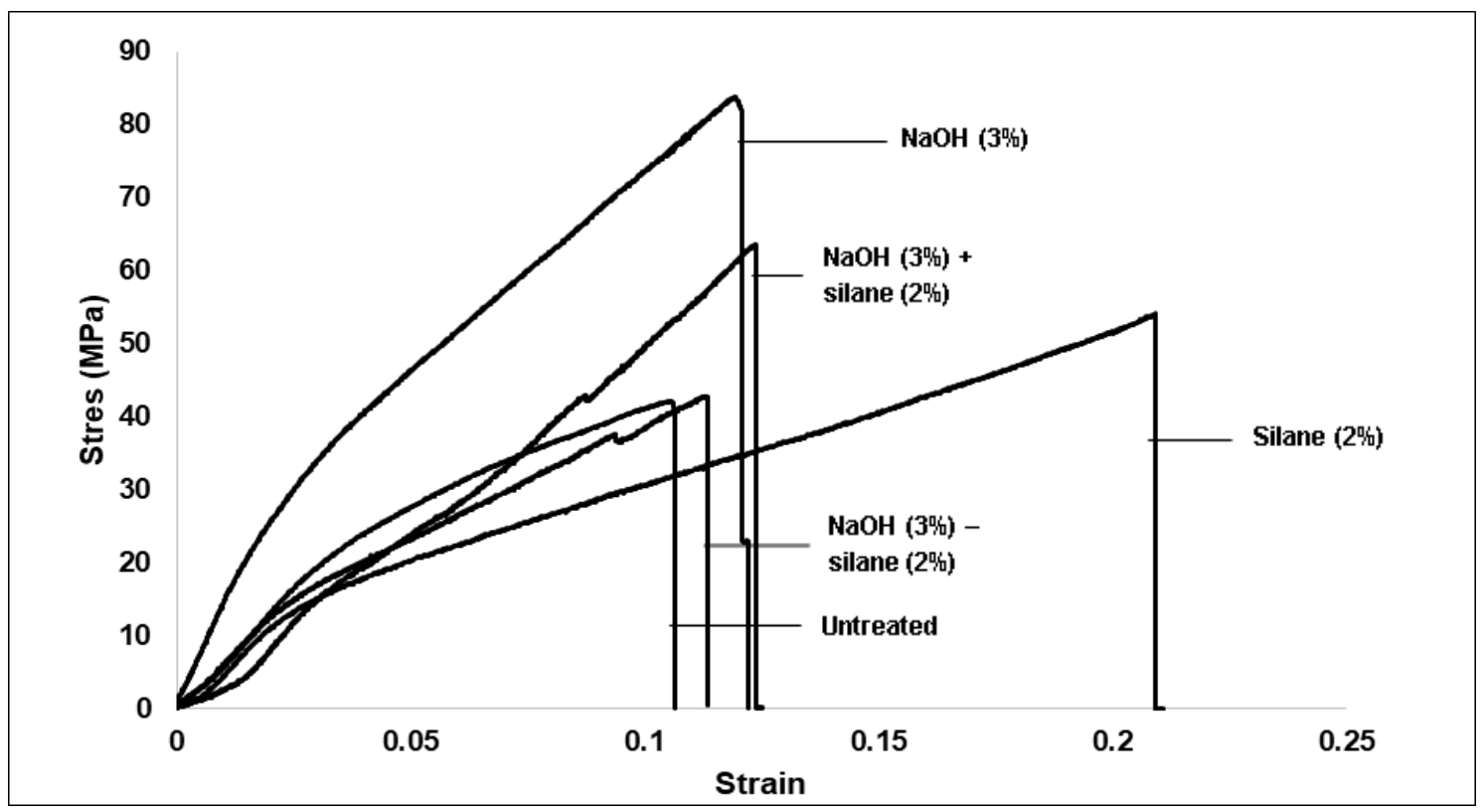

Figure 2. Stress-strain curves of untreated and treated OPEFB fibers.

The $\mathrm{NaOH}(3 \%)$ - silane $(2 \%)$ treated fiber exhibits the closest value compared to untreated fiber. However, incremental ultimate strength and strain are not much different. This result contradicts hemp fibers, whereby a previous study claimed that the performance of multistage $\mathrm{NaOH}$ and silane treated was similar with single $\mathrm{NaOH}$ treated [42].

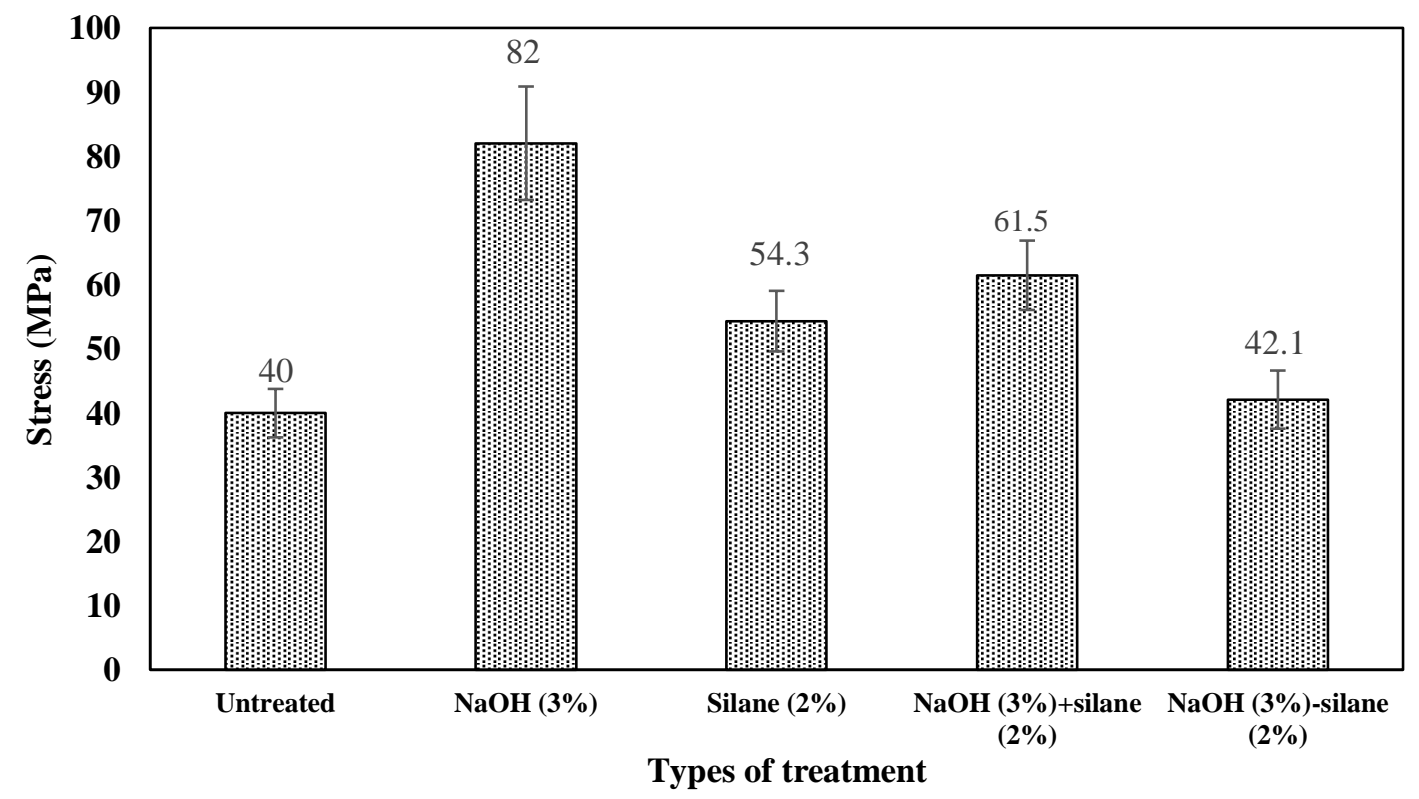

Figure 3. Ultimate tensile strength of untreated and treated OPEFB fibers.

This disagreement is believed to be due to the differentiation of cellulose, hemicellulose, and lignin fractions and the soaking time between these two fibers set. The cellulose fractions of OPEFB and hemp fibers are $49.6 \%$ and $86.6 \%$, respectively. On the other hand, the hemicellulose fractions of OPEFB and hemp fibers are $29.2 \%$ and $6 \%$, respectively, while the lignin fractions are $21.2 \%$ and $7.4 \%$, respectively $[5,25]$. The poor results of OPEFB fibers in $\mathrm{NaOH}(3 \%)$ - silane $(2 \%)$ treated is due to low fractions of hydrophobic and high 
fractions of hydrophilic elements in the fibers (i.e., more moisture is trapped in the fiber structure). Furthermore, a double stage with a different chemical to increase the cellulose fraction is suspected of having damaged the fiber constituents. Also, the coating effects of silane $(2 \%)$ for post- $\mathrm{NaOH}(3 \%)$ were unable to prolong the strain significantly.

Nevertheless, the mixture of $\mathrm{NaOH}(3 \%)+$ silane $(2 \%)$ treatments presented different results. The ultimate tensile strength is slightly increased when compared to untreated and even better when compared to single silane $(2 \%)$ treatment. This treatment method is thought to change the surface roughness, raise the cellulose and hemicellulose fraction, and coat the fibers simultaneously. In terms of fiber performance, it is found that the effects of $\mathrm{NaOH} \mathrm{(3 \% )} \mathrm{are} \mathrm{in}$ contrast to silane (2\%). The highest ultimate tensile strength was achieved after single $\mathrm{NaOH}$ (3\%) treatment, as did the strain. The strain of the fibers was unable to be turned into better results due to the coating effects of silane (2\%). Simultaneously, the coating effects on the fiber resulted in a decrease in fiber strength. The most important finding is that both chemical substances could not adapt by the fibers to modify constituents to obtain better properties due to an uncertain reaction for $\mathrm{NaOH}(3 \%)$ and silane $(2 \%)$ when mixed directly in one treatment solution.

Figure 4 shows the average Young's modulus of the untreated and multiple treated OPEFB fibers. Upon comparison with untreated fibers, Young's modulus of the fibers was markedly increased by the chemical treatments except for the $\mathrm{NaOH}(3 \%)$ - silane (2\%). The decreasing of Young's modulus on $\mathrm{NaOH}(3 \%)$ - silane $(2 \%)$ treated is believed due to the damage caused by a treatment mixture and method change, causing the cellulose in the fiber to partially change from crystalline cellulose I into amorphous cellulose II [43]. In addition, this decreasing behavior is also induced by the degree of degradation of cellulose chains upon treatment [44]. A maximum Young's modulus of $1.05 \mathrm{GPa}$ was achieved with the silane (2\%) treated fibers. Young's modulus slightly increased from $0.82 \mathrm{GPa}$ for the untreated fiber to $1.05 \mathrm{GPa}$ for silane (2\%) treated fiber, which is an increment of $28 \%$. This is followed by $\mathrm{NaOH}(3 \%)$ treated, $\mathrm{NaOH}(3 \%)+$ silane $(2 \%)$ treated, untreated, and $\mathrm{NaOH}(3 \%)$ - silane $(2 \%)$ treated at $0.94 \mathrm{GPa}, 0.87 \mathrm{GPa}, 0.82 \mathrm{GPa}$, and $0.79 \mathrm{GPa}$ respectively. Except for the $\mathrm{NaOH}$ $(3 \%)$ - silane $(2 \%)$ treated that displays a 3.7\% decrease in Young's modulus, the $\mathrm{NaOH}(3 \%)$ and $\mathrm{NaOH}(3 \%)+$ silane $(2 \%)$ treated are increased by about $14.6 \%$ and $6.1 \%$ respectively.

The highest Young's modulus for the silane (2\%) treatments corresponds with the highest fiber strain before breaking. Moreover, it is found that the higher strain experienced the fibers' higher elastic and plastic characteristics. As silane (2\%) treatment reactions, the increasing fractions of cellulose and hemicellulose and coating effects have caused the increase in the elastic and plastic region of the fibers. Hence, this proves that the silane $(2 \%)$ treated fiber has a stable covalent bond to the chemisorbed cell wall onto the fiber surface, as claimed by Godara [41].

Figure 5 exhibits the average toughness of the untreated and multiple treated OPEFB fibers. The toughness of the fibers determines the balance between ultimate tensile strength and strain at break, which is a brittle-ductile indicator. The $\mathrm{NaOH} \mathrm{(3 \% )} \mathrm{presents} \mathrm{the} \mathrm{highest}$ toughness at $5.4 \mathrm{MJ} / \mathrm{m}^{3}$ and increases by $157.1 \%$ compared to untreated fibers. This is followed by silane $(2 \%), \mathrm{NaOH}(3 \%)+$ silane $(2 \%), \mathrm{NaOH}(3 \%)$ - silane $(2 \%)$, and untreated for 5.2 $\mathrm{MJ} / \mathrm{m}^{3}, 3.3 \mathrm{MJ} / \mathrm{m}^{3}, 2.2 \mathrm{MJ} / \mathrm{m}^{3}$, and $2.1 \mathrm{MJ} / \mathrm{m}^{3}$ respectively. Notably, the toughness of the fibers due to silane $(2 \%), \mathrm{NaOH}(3 \%)+$ silane $(2 \%)$, and $\mathrm{NaOH}(3 \%)$ - silane $(2 \%)$ treatment have increased by $147.6 \%, 57.1 \%$, and $4.8 \%$ respectively in comparison against untreated fiber. 


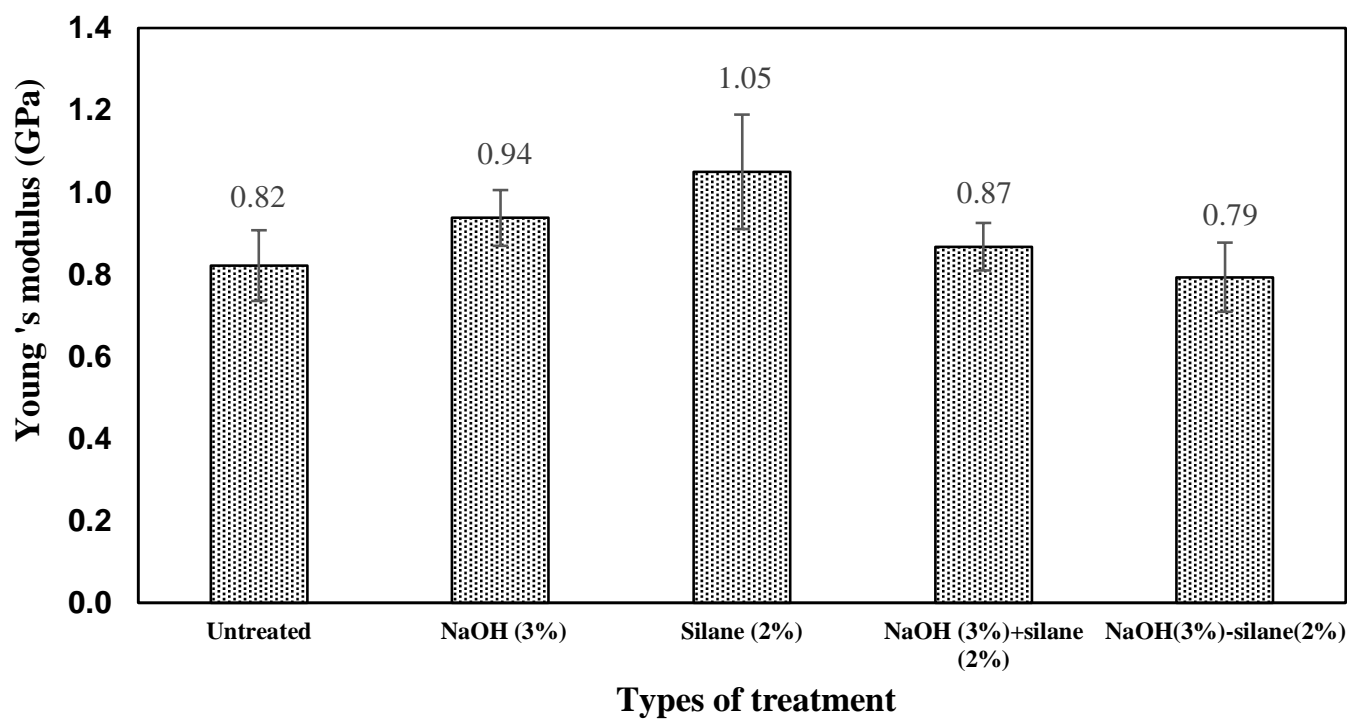

Figure 4. Young's modulus of untreated and treated OPEFB fibers.

Next, the ultimate tensile strength of the $\mathrm{NaOH}(3 \%)$ treated fibers is highest compared with the untreated and other multiple treated fibers, although the strain at break exhibits small changes. On the other hand, silane (2\%) treated fibers give a higher toughness value due to significant strain changes. Despite having the maximum toughness, the $\mathrm{NaOH}(3 \%)$ treated fibers are considered brittle, whereas the silane $(2 \%)$ treated fibers are exceptionally ductile. Both treated fibers have good energy absorption during a tensile test, although distinct behaviors are contradicted.

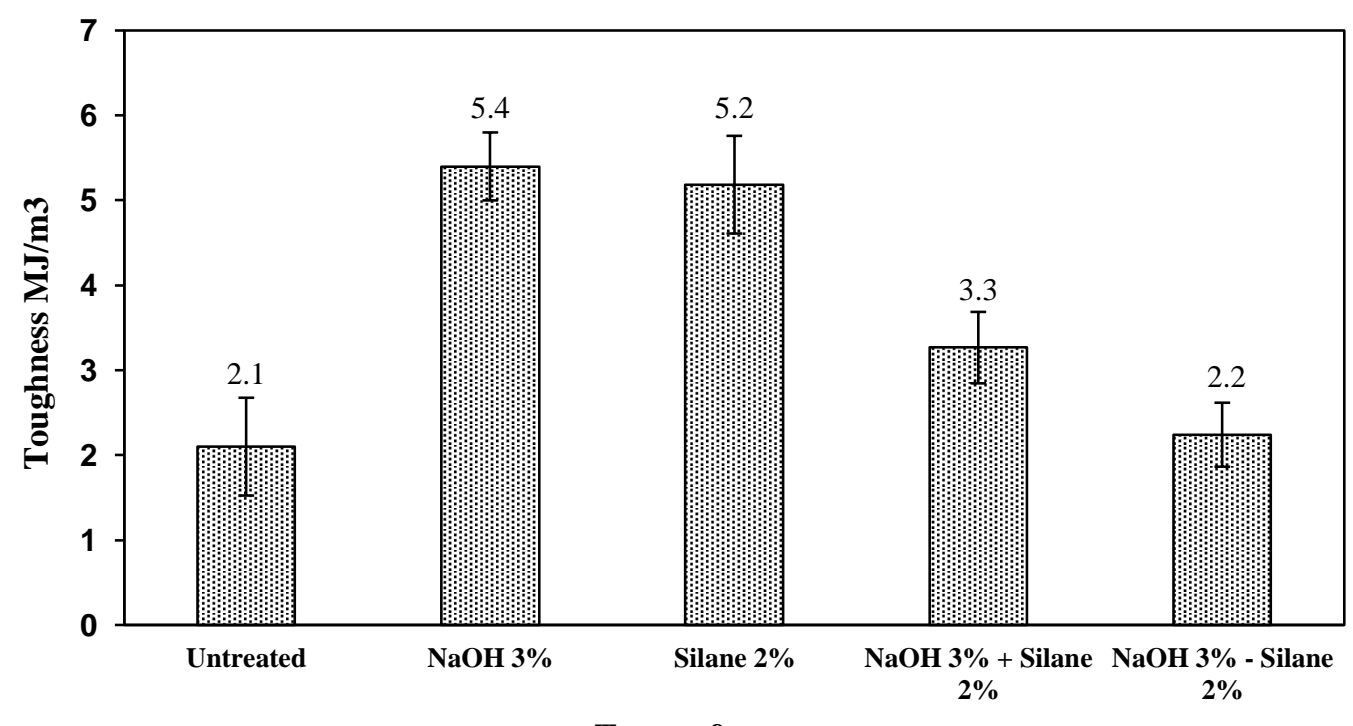

Types of treatment

Figure 5. Toughness of untreated and treated OPEFB fibers.

This condition gives a selection for future application, whether one is inclined to toughbrittle or tough-ductile characteristics. The $\mathrm{NaOH}(3 \%)+$ silane $(2 \%)$ treated fibers exhibit moderate toughness, and $\mathrm{NaOH}(3 \%)$ - silane $(2 \%)$ treated and untreated fibers display poor toughness due to poor strain at breaking point. In general, a single chemical treatment can increase the toughness of the OPEFB fibers due to changes to the fiber's physicals and constituents. However, the multiple chemical treatments were unable to increase the toughness 
into significant value, although the same chemical substances were employed. It is suspected that these chemical treatments reacted rather inefficiently compared with their single reaction on the fibers.

\subsection{Morphology analysis.}

The surface morphological study of the fibers is important to observe the changes that occurred on the surface of OPEFB fiber caused by multiple treatments. Figure 6 exhibits the surface morphologies for untreated and multiple-treated OPEFB fibers. The untreated fibers display the fairly smooth surface roughness and the impurities present on the fiber surface, as shown in Figure 6(a). Figure 6(b-d) shows the morphology image of the $\mathrm{NaOH}(3 \%)$, silane $(2 \%)$, and $\mathrm{NaOH}(3 \%)+$ silane $(2 \%)$ treated fiber. The damaged textures on the surfaces of the fibers can be observed. The $\mathrm{NaOH}(3 \%)$ treated fiber demonstrated a rougher surface than silane $(2 \%)$ and $\mathrm{NaOH}(3 \%)+$ silane $(2 \%)$ treated fiber. These rough surfaces would be believed to promote good interfacial bonding between fibers and the matrix when used as reinforcement materials in composites [45-48]. However, if these rough surfaces exceed the desired stage, it could interrupt the mechanical properties of the fibers [33,34]. Figure 6(e) shows the $\mathrm{NaOH}(3 \%)$ - silane $(2 \%)$ treated fiber. It can be observed that the surface roughness is identically smooth on the fiber surfaces compared to untreated fiber. The smooth surface roughness is believed to be due to the coating effect of silane (2\%) treatment after $\mathrm{NaOH}(3 \%)$ treatment subsequently.

Based on the OPEFB single fiber test result and morphological study, the OPEFB fibers will be treated using $\mathrm{NaOH}(3 \%)$ prior to composite fabrications. The main selection factors are the ultimate tensile strength, toughness, and surface roughness of the fibers. Higher ultimate tensile strength of the fibers is required to ensure the fibers bond adequately with the matrix and be able to withstand high resistance to break during load exertion. The high resistance to breakage of the fibers promotes a good strength of the composite structure. Meanwhile, the toughness presents the ability of the fibers to absorb the energy during the load exertion and is expected to complement the composite bonding. Furthermore, the surface roughness of the fibers is believed to influence better interfacial bonding between fibers and matrix in composite reinforcement.

\subsection{Composite test.}

Figure 7 shows the stress-strain responses for selected untreated and treated OPEFB based fiber composites with various fiber/epoxy fractions. The ductility of the treated composites seems to have increased for all fiber/epoxy fractions. The ductility is identified based on a higher strain value that a specific composite can sustain during the tensile test, while a lower strain value could be considered brittle. As for the treated composites, the 40:60 exhibits the most ductile fiber/epoxy fraction, followed by 30:70, 20:80, and 10:90. 


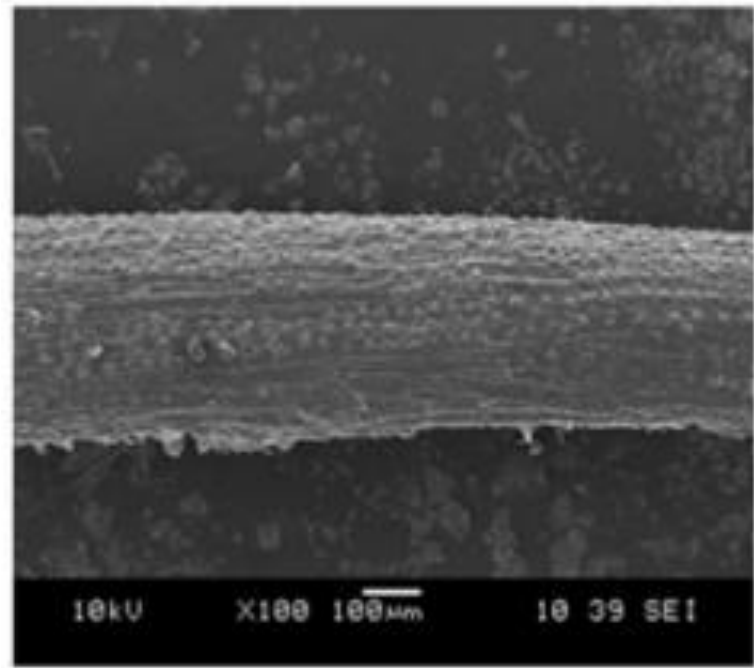

(a) Untreated

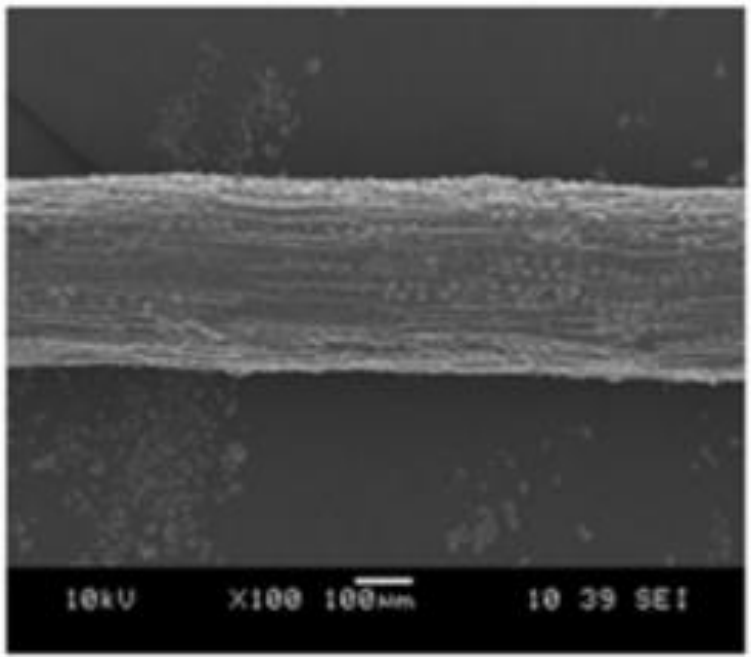

(c) Silane (2\%)

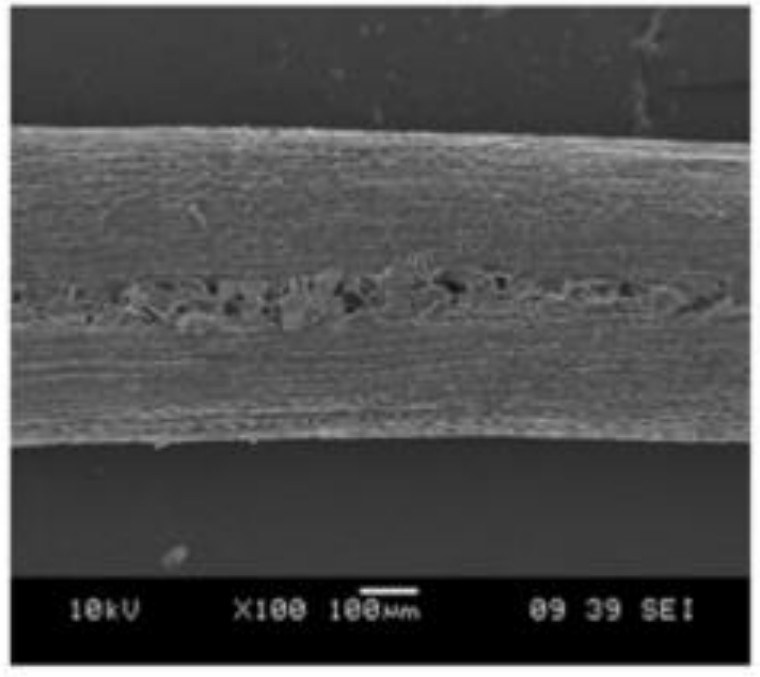

(b) $\mathrm{NaOH}(3 \%)$

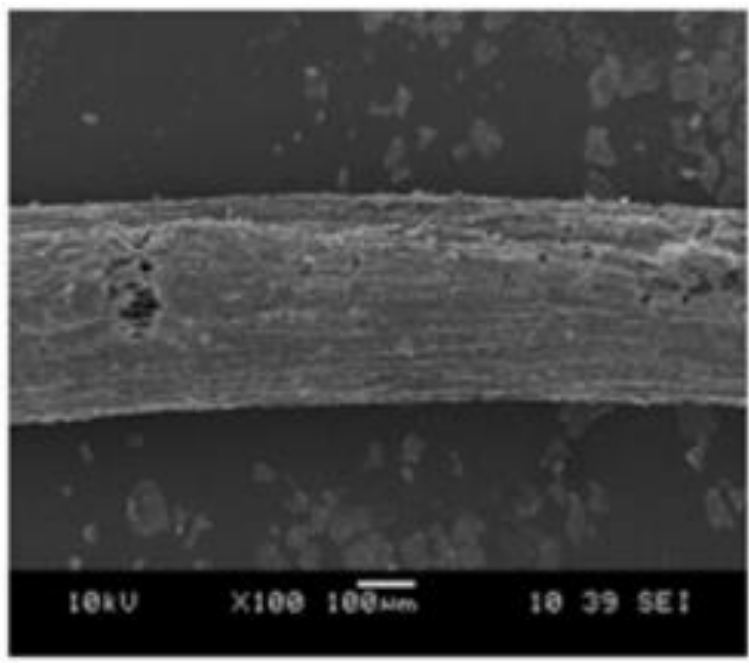

(d) $\mathrm{NaOH}(3 \%)+$ Silane $(2 \%)$

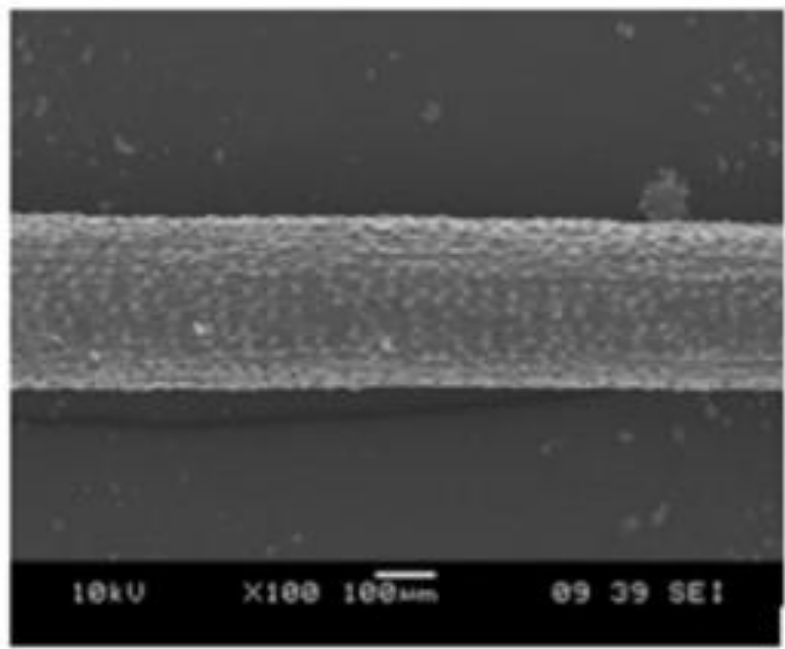

(e) $\mathrm{NaOH}(3 \%)$ - Silane (2\%)

Figure 6. Surface morphologies for untreated and multi-treated OPEFB fibers. 
Meanwhile, the untreated composites with 40:60 fiber/epoxy fraction demonstrate the highest ductility, followed by 20:80,30:70, and 10:90. The ductility of the treated composites 40:60, 30:70, 20:80, and 10:90 fiber/epoxy fractions have increased by about $64.7 \%, 171.7 \%$, $42 \%$, and $160.3 \%$, respectively when compared against untreated composites.

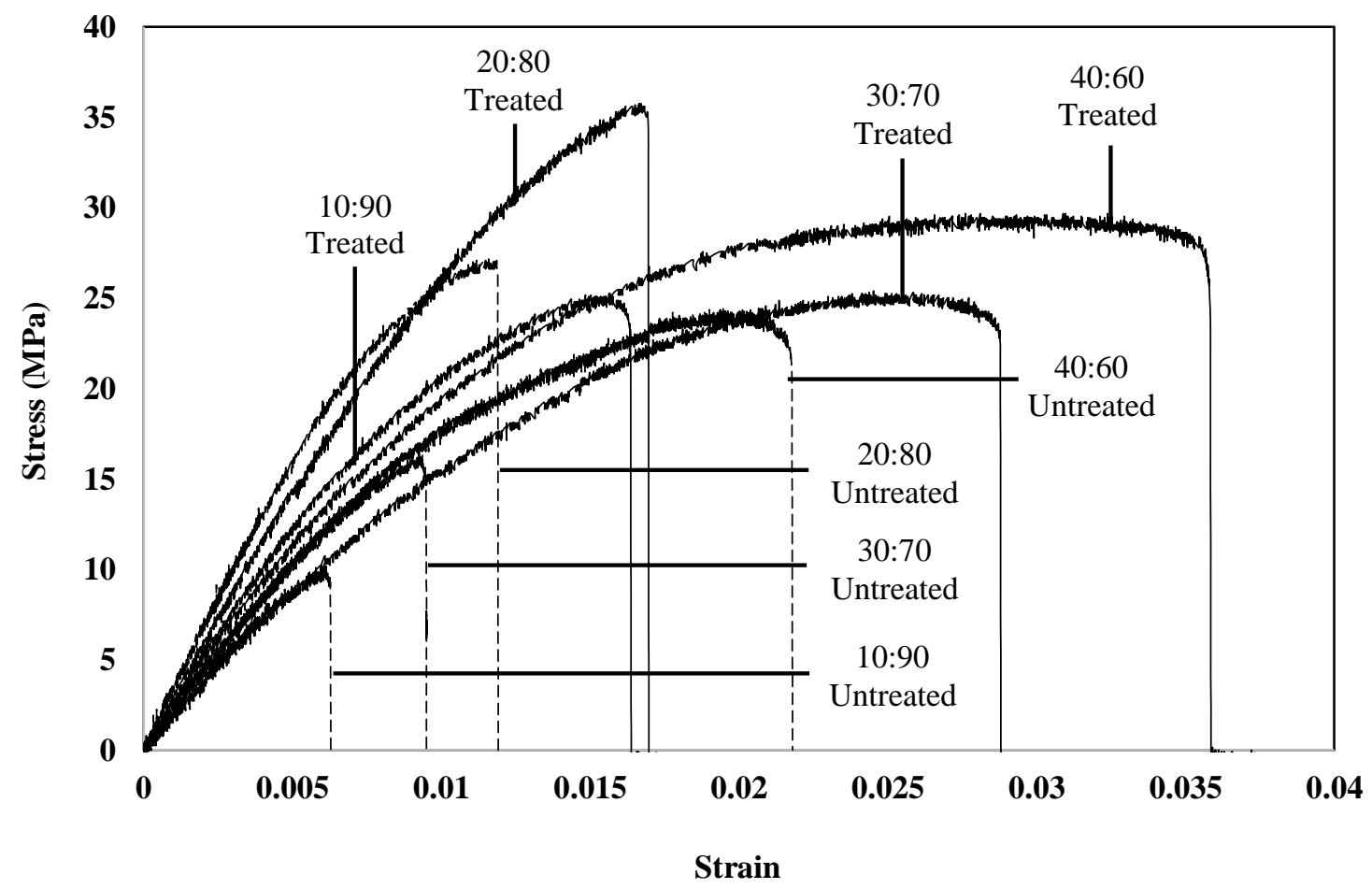

Figure 7. Stress-strain curves of untreated and treated OPEFB fibers reinforced composite in various fiber/epoxy fractions.

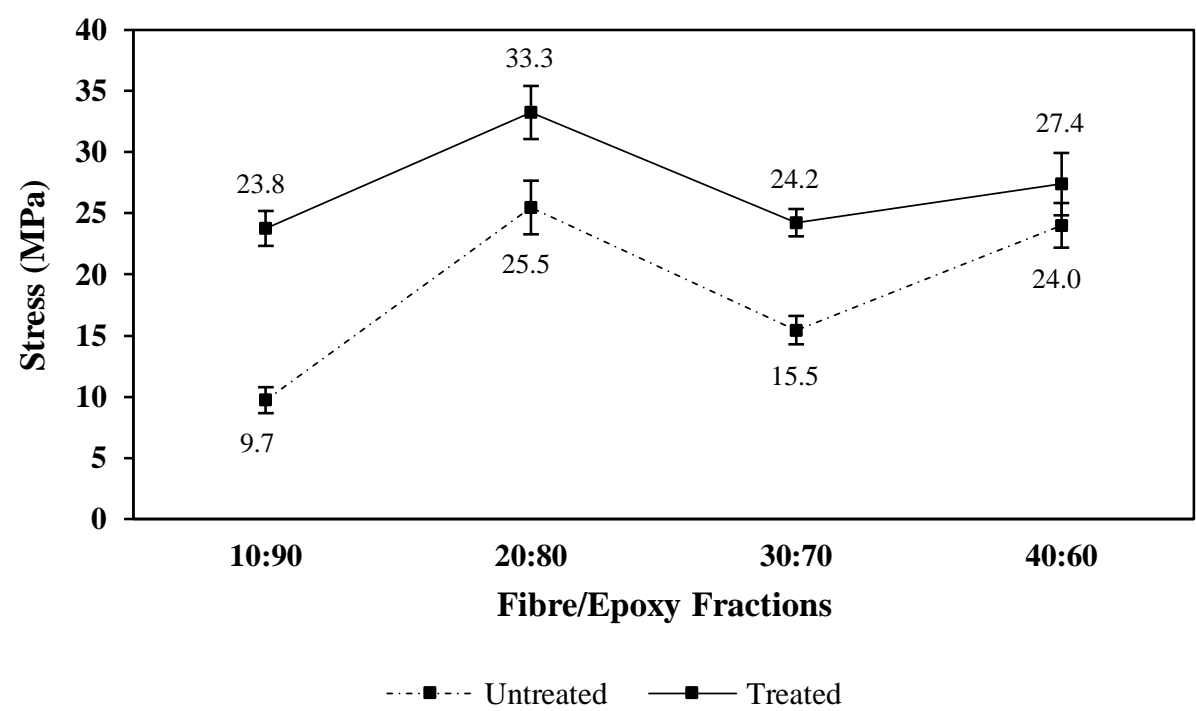

Figure 8. Ultimate tensile strength of untreated and treated OPEFB fibers reinforced composite in various fiber/epoxy fractions.

The ultimate tensile stress of treated composites also increases when compared to untreated composites. The treated composite with 20:80 fiber/epoxy fraction demonstrates the highest tensile stress, $33.3 \mathrm{MPa}$, which is an increase of $30.5 \%$ compared to untreated composite, 25.5 MPa. The 10:90 fiber/epoxy fraction shows the most significant improvement in which both treated and untreated composites are at $23.8 \mathrm{MPa}$ and 9.7 $\mathrm{MPa}$, respectively. This corresponds to an increase of about $145.3 \%$. Meanwhile, the treated and untreated 
composites of 30:70 fiber/epoxy fraction are at 24.2 MPa and 15.5 MPa, respectively, with approximately $56.1 \%$ increments from the untreated specimen. The untreated and treated composites of 40:60 fiber/epoxy fraction achieved 27.4 MPa and $24 \mathrm{MPa}$, respectively. It shows a $14.2 \%$ improvement of ultimate tensile stress for the treated composite. Figure 8 illustrates the detailed observation of the average ultimate tensile stress for various fiber/epoxy fractions.

Furthermore, there is a clear increment in Young's modulus average for the treated composites, as shown in Figure 9. The highest Young's modulus of $1.9 \mathrm{GPa}$ was achieved by the treated composites of 20:80 fiber/epoxy fraction while the untreated composite is at 1.4 $\mathrm{GPa}$, which was an increment of 35.7\%. However, the most significant increment was the 30:70 fiber/epoxy fraction with an approximate gain of $166.7 \%$. The Young's modulus of this fraction for untreated and treated composites was $0.6 \mathrm{GPa}$ and $1.6 \mathrm{GPa}$, respectively. The treated composite of 40:60 fiber/epoxy fraction achieved 1.5 GPa, which is an increase of about $87.5 \%$ compared with untreated composite, $0.8 \mathrm{GPa}$. The treated composite of 10:90 fiber/epoxy fraction had also demonstrated a significant increment in Young's modulus value by about $83.3 \%$ compared to untreated composite.

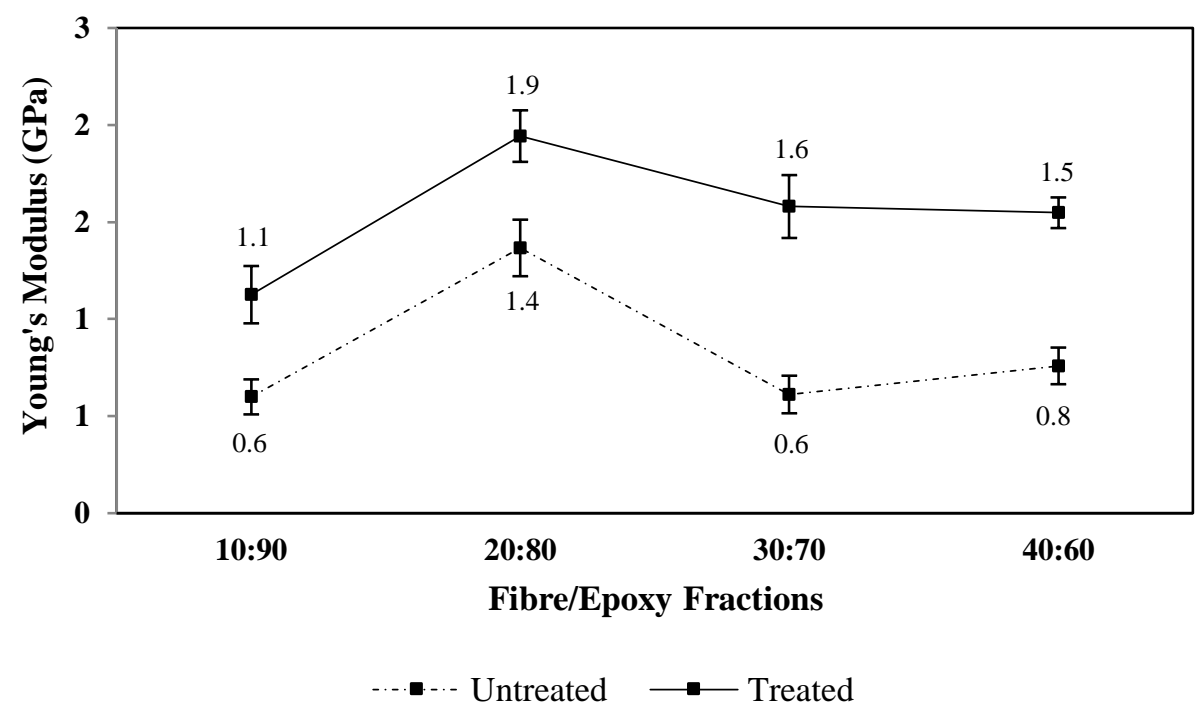

Figure 9. Young's modulus of untreated and treated OPEFB fibers reinforced composite in various fiber/epoxy fractions.

Moreover, the 40:60 fiber/epoxy fraction composites display the most significant toughness average, as illustrated in Figure 10. The toughness of treated and untreated composites for this fraction is $805 \mathrm{~kJ} / \mathrm{m}^{3}$ and $333 \mathrm{~kJ} / \mathrm{m}^{3}$, respectively, increasing about $141.7 \%$. Then, it is followed by 30:70 fiber/epoxy fraction, $465 \mathrm{~kJ} / \mathrm{m}^{3}$, and $95 \mathrm{~kJ} / \mathrm{m}^{3}$ for treated and untreated composites, respectively, with a significant increase of about $389.5 \%$. The toughness of the 20:80 fiber/epoxy fraction for treated composite $\left(343 \mathrm{~kJ} / \mathrm{m}^{3}\right)$ has improved by $88.5 \%$ over the untreated composites $\left(182 \mathrm{~kJ} / \mathrm{m}^{3}\right)$. The 10:90 fiber/epoxy fraction, on the other hand, presents the lowest toughness with the treated and untreated composite values of $214 \mathrm{~kJ} / \mathrm{m}^{3}$ and $68 \mathrm{~kJ} / \mathrm{m}^{3}$. Nevertheless, it shows that the treated composite has improved its toughness by $214.7 \%$ over the untreated composite.

Overall, the treated OPEFB fibers reinforced composites demonstrate better ultimate tensile strength, strain to failure, Young's modulus, and toughness in all-fiber/epoxy fractions. These improvements are believed to be due to changes in the fiber cellulose crystallinity, and the treated process involves removing the weak amorphous component, thus enhancing the 
bonding with the matrix [28,29]. Hence, this enables the fibril to rearrange more compactly and enhances the tensile properties [49]. Besides, the treated fibers are presumed to provide a better interlocking mechanism between the matrix and fibers in reinforced composites that improve their interfacial bonding [28,31]. Furthermore, previous studies have also proved that the treated fibers composite promotes high resistance to continuous elongation increase in Young's modulus as well as overall improvement in other mechanical properties [21,32]. Also, the treated composites significantly increased the tensile properties due to better fiber surface impurities and surface roughness that promote better bonding with the matrix [52]. Additionally, the $3 \% \mathrm{NaOH}$ treatment removes the lignin and cellulose layer around the fibers, decreasing the fiber wettability and thus increasing the overall surface area of interaction between fiber and matrix, resulting in better bonding strength and tensile strength [53]. Moreover, the treated fibers tend to take out a certain portion of hemicellulose and lignin covering the fiber surface, exposing the cellulose structure to better adhesion with the matrix [42].

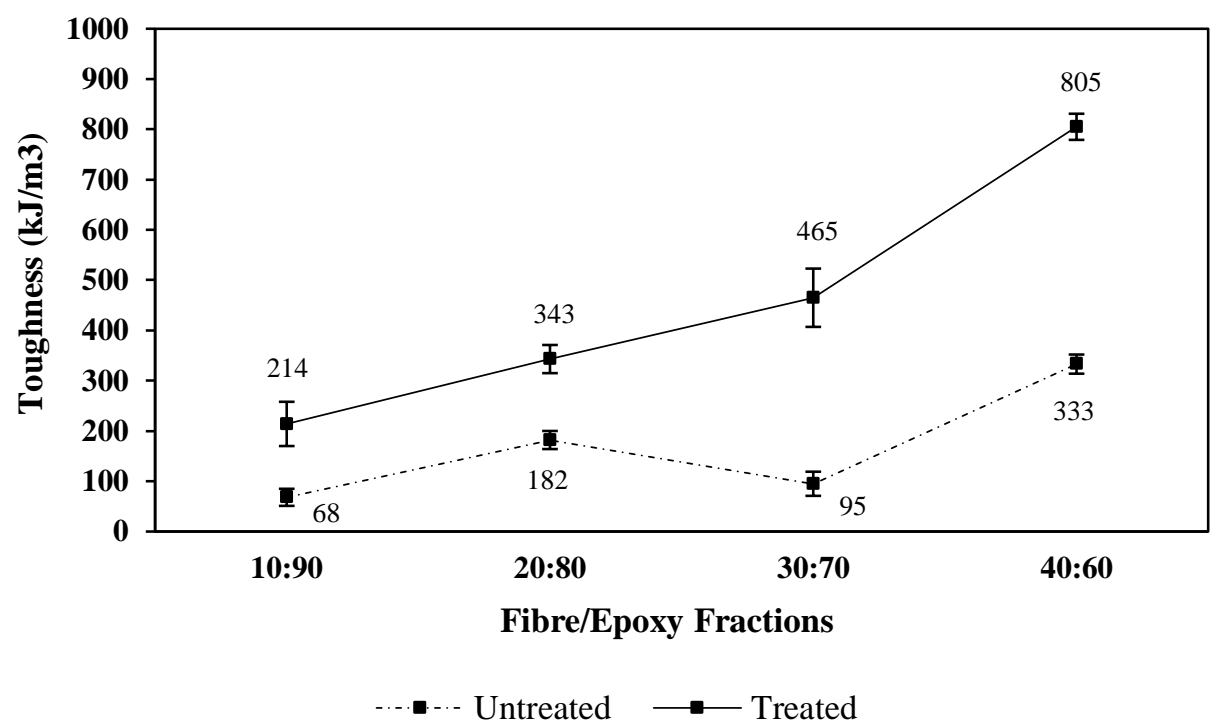

Figure 10. Toughness of untreated and treated OPEFB fibers reinforced composite in various fiber/epoxy fractions.

Based on the observation, the ultimate tensile strength, Young's modulus, and toughness of different fiber/epoxy fractions are varied. The difference in fiber content in the composite reveals different performances, and there is a fluctuating pattern between the fractions. In general, although higher fiber content is desired to achieve higher performance, other factors such as the types of fiber, types of fiber treatments, arrangement of fibers, and methods of composites fabrication are also crucial [52]. Furthermore, the previous natural fiber composite studies have demonstrated that the presence of fiber in the polymeric matrix at an acceptable percentage increases composite strength and modulus, although there is no distinct increasing or diminishing pattern [54]. Besides that, past research has found that treatment effects on certain fiber constituents, specifically the proportion of cellulose, hemicellulose, and lignin, were variable, resulting in an inconsistent pattern of performance between fiber/matrix fractions [42]. Therefore, the amount of cellulose, hemicellulose, and lignin in the fiber will profoundly impact the bonding strength with the matrix.

Referring to the ultimate tensile strength and Young's modulus results, the 20:80 fiber/epoxy fraction of OPEFB composites presents the highest values for both parameters. This fraction promotes the optimum bonding between fibers and matrix for good strength and 
elasticity. The presence of $20 \%$ fibers in the composite improves the brittleness and strength of the epoxy. This is due to the excellent adhesive between the fibers and epoxy, as the epoxy volume is significant. However, it is found that the increment of fiber volume depicts the decreasing of the strength and Young's modulus. The increment of fibers is presumed to have weakened the adhesive between fibers and epoxy. The lower volume of epoxy was unable to bind the fibers properly, hence generating voids in the composite. Compared to the 10:90 fiber/epoxy fraction, its strength and Young's modulus is the lowest due to the inadequate presence of fibers to reinforce the matrix.

Meanwhile, the 40:60 fiber/epoxy fraction achieves the maximum toughness of 805 $\mathrm{kJ} / \mathrm{m} 3$, demonstrating lower strength and Young's modulus compared to the 20:80 fiber/epoxy fraction. It shows that a higher presence of fibers has increased the strain of the composites hence notably improving its ductility. Further, the $40 \%$ fibers content contributes to the balance between strength and ductility of the composites. Thus, it helps the composite in absorbing energy during load exertion. The higher presence of fibers in the composite causes the energyabsorbing characteristics of the fibers to dominate the brittleness characteristics of epoxy and, at the same time, maintain its strength.

\section{Conclusions}

The effects of multiple chemical treatments of OPEFB fibers and various fractions of OPEFB fibers reinforced composites on mechanical properties were investigated. The fibers were treated using $\mathrm{NaOH}(3 \%)$, silane (2\%), $\mathrm{NaOH}(3 \%)+$ silane (2\%), and $\mathrm{NaOH} \mathrm{(3 \% )-}$ silane $(2 \%)$ prior to the tensile test. Meanwhile, the reinforced composites were fabricated in 10:90, 20:80, 30:70, and 40:60 fiber/epoxy fractions using selected treated fibers. Based on the results of both studies, the following conclusions can be drawn:

1. The maximum ultimate tensile strength for the single fiber test was recorded for the $\mathrm{NaOH}(3 \%)$ treatment which is $82 \mathrm{MPa}$. This treatment experienced better mechanical interlocking due to increases in the surface roughness and the amount of cellulose exposed on the fiber surface, thus increasing the number of possible reaction sites.

2. The highest Young's modulus for the single fiber test is $1.05 \mathrm{GPa}$ using the silane $(2 \%)$ treatment. Silane $(2 \%)$ treatment increases the fractions of cellulose and hemicellulose and the coating effects on the fiber constituents. These reactions are believed to have increased the area of the elastic and plastic regions of the fibers. The treated fiber using silane (2\%) was also found to have a stable covalent bond to the cell wall that is chemisorbed onto the fiber surface.

3. The $\mathrm{NaOH}(3 \%)$ and silane (2\%) treated fibers revealed the highest toughness of 5.4 $\mathrm{MJ} / \mathrm{m}^{3}$ and $5.2 \mathrm{MJ} / \mathrm{m}^{3}$, respectively. It can be concluded that a single chemical treatment is able to increase the toughness of the OPEFB fibers due to changes to the fiber physicals and constituents. Meanwhile, multiple chemical treatments were unable to increase the toughness into significant value, albeit using the same chemical solution. This could be because the combined chemical treatment reacted inefficiently with the fibers compared to the solo chemical treatment.

4. The treated 20:80 fiber/epoxy fraction of OPEFB fibers composite displayed better ultimate tensile strength and Young's modulus compared to other fractions at $33.3 \mathrm{MPa}$ and 1.9 GPa, respectively. The treated fiber composite retains the crystalline components and enhances bonding with the matrix. Besides that, the treated fiber composite was presumed to provide a better interlocking mechanism between the matrix and fibers in reinforced 
composites, thus improving their interfacial bonding. Also, the treated fibers composites have significantly increased the tensile properties due to better fibers surface impurities and surface roughness, promoting better bonding with the matrix. Furthermore, the treated composite with 20:80 fiber/epoxy fractions demonstrated the optimal fiber and matrix mixture balance. The strength of the fibers is well blended and complimented the strength of the epoxy.

5. The 40:60 fibers/epoxy fraction of treated OPEFB fibers composite, on the other hand, exhibited the maximum toughness of $805 \mathrm{~kJ} / \mathrm{m}^{3}$. The higher fibers content causes better energy absorption compared to other fractions. This is due to the excellent balancing between strength and ductility of the composites.

\section{Funding}

This research was funded by Universiti Putra Malaysia and Sime Darby Research through UPM-SDR Grant Number 9025-00002.

\section{Acknowledgments}

The authors would like to be obliged to the Faculty of Mechanical Engineering Technology, Universiti Malaysia Perlis (UniMAP) for providing laboratory facilities, Motorsport Technology Unit (MOTECH) UniMAP for providing financial assistance, and Universiti Putra Malaysia (UPM) as a collaborative partnership.

\section{Conflicts of Interest}

The authors declare no conflict of interest.

\section{References}

1. Rozman, H.D.; Ahmadhilmi, K.R.; Abubakar, A. Polyurethane (PU) - Oil Palm Empty Fruit Bunch (EFB) Composites: The Effect of EFBG Reinforcement in Mat Form and Isocyanate Treatment on the Mechanical Properties. Polym. Test. 2004, 23, 559-565, https://doi.org/10.1016/j.polymertesting.2003.11.004.

2. Hasan, K.M.F.; Horv, G.; Alp, T. Potential Natural Fiber Polymeric Nanobiocomposites: A Review. Polymers 2020, 12, 1072, https://doi.org/10.3390/polym12051072.

3. Chowdhury, M.A.; Hossain, S. A Review on Tensile and Flexural Properties of Fiber-Reinforced Polymer Composites.J. Polym. Sci. A Polym. Chem. 2020, 7, 16-26, https://doi.org/10.9790/019X-07051626.

4. Kandemir, A.; Pozegic, T.R.; Hamerton, I.; Eichhorn, S.J.; Longana, M.L. Discontinuous Fibre Composite Materials. Materials 2020, 13, 2129, https://doi.org/10.3390/ma13092129.

5. Talimi, M. Characterization of Natural Fibre Reinforced Biodegradable Composites, 2011.

6. Stanciu, M.D.; Ioan, C. Mechanical Properties of GFRPs Exposed to Tensile , Compression and Tensile Tensile Cyclic Tests. Polymers 2021, 13, 898, https://doi.org/10.3390/polym13060898.

7. Bourhis, E.Le; Touchard, F. Mechanical Properties of Natural Fiber Composites. Encyclopedia of Materials : Composites. 2021, 3, 135-148, https://doi.org/10.1016/B978-0-12-819724-0.00009-4.

8. Elsad, R.A.; El-wazery, M.S.; El-kelity, A.M. Effect of Water Absorption on the Tensile Characteristics of Natural / Synthetic Fabrics Reinforced Hybrid Composites. Int. J. Eng. 2020, 33, 2339-2346, https://doi.org/10.5829/ije.2020.33.11b.24.

9. Ruzuqi, R. Tensile Strength Analysis of Polymer Composite Materials Fiber Reinforced in The Fiber Boat Application. J. Res. Opin. 2020, 7, 2763-2769, https://doi.org/10.15520/jro.v7i8.74.

10. Al-hassany, M.O.A.; Al-dulaimy, A.; Al-sammarraie, A.; Fares, A. Effect of Fiberglass Form on the Tensile and Bending Characteristic of Epoxy Composite Material. AIMS Materials Science 2020, 7, 583-595, https://doi.org/10.3934/matersci.2020.5.583.

11. Charca, S.; Candiotti, S. Mechanical Properties Characterization of the Ichu Fibers Composites. 2020. https://doi.org/10.1088/1757-899X/942/1/012010.

12. Mulenga, T.K.; Ude, A.U.; Vivekanandhan, C. Concise Review on the Mechanical Characteristics of Hybrid Natural Fibres with Filler Content. AIMS Materials Science 2020, 7, 650-664, https://doi.org/10.3934/matersci.2020.5.650.

13. Cederløf, H.; Jonas, D.; Bent, F. Experiment Characterisation of Fibre / Matrix Interfacial Fracture Energy 
Using the Single Fibre Peel Experiment. IOP Conf. Ser.: Mater. Sci. Eng. 2020, 942, 012029, https://doi.org/10.1088/1757-899X/942/1/012029.

14. Beter, J.; Schrittesser, B.; Maroh, B.; Sarlin, E.; Fuchs, P.F.; Pinter, G. Polymers Comparison and Impact of Di Ff Erent Fiber Debond Techniques on Fiber Reinforced Flexible Composites. Polymers 2020, 12, 472, https://doi.org/10.3390/polym12020472.

15. Salih, A.A.; Zulkifli, R.; Azhari, C. H. Tensile Properties and Microstructure of Alkali Treatment. Fibers 2020, 8, 26, https://doi.org/10.3390/fib8050026.

16. Faizi, M.K.; Shahriman, A.B.; Abdul Majid, M.S.; Shamsul, B.M.T.; Ng, Y.G.; Basah, S.N.; Cheng, E. M.; Afendi, M.; Zuradzman, M.R.; Wan, K.; Hazry, D. An Overview of the Oil Palm Empty Fruit Bunch (OPEFB) Potential as Reinforcing Fibre in Polymer Composite for Energy Absorption Applications. MATEC Web Conf. 2017, 90, 01064, https://doi.org/10.1051/matecconf/20179001064.

17. Nasution, H.; Pandia, S.; Maulida; Sinaga, M.S. Impact Strength and Thermal Degradation of Waste Polypropylene (WPP)/Oil Palm Empty Fruit Bunch (OPEFB) Composites: Effect of Maleic Anhydride -gPolypropylene (MAPP) Addition. Procedia Chem. 2015, 16, 432-437, https://doi.org/10.1016/j.proche.2015.12.075.

18. Roslan, R.; Zakaria, S.; Chia, C.H.; Boehm, R.; Laborie, M.P. Physico-Mechanical Properties of Resol Phenolic Adhesives Derived from Liquefaction of Oil Palm Empty Fruit Bunch Fibres. Ind. Crops Prod. 2014, 62, 119-124, https://doi.org/10.1016/j.indcrop.2014.08.024.

19. Jawaid, M.; Abdul Khalil, H.P.S.; Abu Bakar, A. Mechanical Performance of Oil Palm Empty Fruit Bunches/Jute Fibres Reinforced Epoxy Hybrid Composites. Mater. Sci. Eng. A 2010, 527, 7944-7949, https://doi.org/10.1016/j.msea.2010.09.005.

20. Khalid, M.; Ratnam, C.T.; Chuah, T.G.; Ali, S.; Choong, T.S.Y. Comparative Study of Polypropylene Composites Reinforced with Oil Palm Empty Fruit Bunch Fiber and Oil Palm Derived Cellulose. Mater. Des. 2008, 29, 173-178, https://doi.org/10.1016/j.matdes.2006.11.002.

21. Rozman, H.D.; Tay, G.S.; Kumar, R.N.; Abusamah, A.; Ismail, H.; Ishak, Z. a M. Polypropylene \pm Oil Palm Empty Fruit Bunch \pm Glass ${ }^{\circledR}$ Bre Hybrid Composites: A Preliminary Study on the Flexural and Tensile Properties. Eur. Polym. J. 2001, 37, 1283-1291, https://doi.org/10.1016/S0014-3057(00)00243-3.

22. Faizi, M.K.; Shahriman, A.B.; Abdul Majid, M.S.; Ahmad, Z.A.; Shamsul, B.M.T.; Ng, Y.G. The Effect of Multiple Surface Treatments on Oil Palm Empty Fruit Bunch ( OPEFB ) Fibre Structure. IOP Conf. Ser. Mater. Sci. Eng. 2018, 429, 012005, https://doi.org/10.1088/1757-899X/429/1/012005.

23. Faizi, M.K.; Shahriman, A.B.; Majid, M.S.A.; Shamsul, B.M.T.; Zunaidi, I.; Ng, Y.G.; Razlan, Z.M.; Wan, W.K. The Effect of Alkaline Treatments Soaking Time on Oil Palm Empty Fruit Bunch (OPEFB) Fibre Structure. IOP Conf. Ser. J. Phys. 2017, 908, 012033, https://doi.org/10.1088/1742-6596/908/1/012033.

24. Faizi, M.K.; Shahriman, A.B.; Abdul Majid, M.S.; Abdul Rahman, M.N.M.; Shamsul, B.M.T.; Ng, Y.G.; Razlan, Z.M.; Wan, W.K.; Hashim, M.S.M.; Rojan, M.A. The Physical Properties Observation of Oil Palm Empty Fruit Bunch ( OPEFB ) Chemical Treated Fibres. IOP Conf. Ser. Mater. Sci. Eng. 2019, 670, 012055, https://doi.org/10.1088/1757-899X/670/1/012055.

25. Malaysian Palm Oil Board (MPOB). Overview of The Malaysian Oil Palm Industry 2014; 2015.

26. Malaysian Palm Oil Board (MPOB). Overview of The Malaysian Oil Palm Industry 2015; 2016.

27. Malaysian Palm Oil Board (MPOB). Overview of The Malaysian Oil Palm Industry 2017; 2018; Vol. i.

28. Malaysian Palm Oil Board (MPOB). Oil Palm Planted Area 2018; 2018; Vol. 2018.

29. Malaysian Palm Oil Board (MPOB). Overview of The Malaysian Oil Palm Industry 2018; 2019; Vol. d.

30. Malaysian Palm Oil Board (MPOB). Overview of The Malaysian Oil Palm Industry 2016; 2017.

31. Malaysian Palm Oil Board (MPOB). Overview of The Malaysian Oil Palm Industry 2019; 2020; Vol. i.

32. (MPOB), M. P. O. B. Oil Palm Planted Area 2019; 2019; Vol. 2019.

33. Awalludin, M.F.; Sulaiman, O.; Hashim, R.; Nadhari, W.N.A.W. An Overview of the Oil Palm Industry in Malaysia and Its Waste Utilization through Thermochemical Conversion, Specifically via Liquefaction. Renew. Sustain. Energy Rev. 2015, 50, 1469-1484, https://doi.org/10.1016/j.rser.2015.05.085.

34. Industry, M.-G. C. of C. and. Oil Palm Biomass \& Biogas in POTENTIALS FOR EUROPEAN SMES; 2017.

35. Yusoff, S. Renewable Energy from Palm Oil - Innovation on Effective Utilization of Waste. J. Clean. Prod. 2006, 14, 87-93, https://doi.org/10.1016/j.jclepro.2004.07.005.

36. ASTM D3039. Standard Test Method for Tensile Properties of Polymer Matrix Composite Materials. Annu. B. ASTM Stand. 2017, 1-13.

37. Faizi, M.K.; Shahriman, A.B.; Abdul Majid, M.S.; Ahmad, Z.A.; Shamsul, B.M.T.; Ng, Y.G. The Effect of Alkaline Treatments with Various Concentrations on Oil Palm Empty Fruit Bunch ( OPEFB ) Fibre Structure. IOP Conf. Ser. Mater. Sci. Eng. 2018, 429, 012006, https://doi.org/10.1088/1757-899X/429/1/012006.

38. Li, X.; Tabil, L.G.; Panigrahi, S. Chemical Treatments of Natural Fiber for Use in Natural Fiber-Reinforced Composites: A Review. J. Polym. Environ. 2007, 15, 25-33, https://doi.org/10.1007/s10924-006-0042-3.

39. Valadez-Gonzalez, A.; Cervantes-Uc, J.M.; Olayo, R.; Herrera-Franco, P.J. Effect of Fiber Surface Treatment on the Fiber-Matrix Bond Strength of Natural Fiber Reinforced Composites. Compos. Part B Eng. 1999, 30, 309-320, https://doi.org/10.1016/S1359-8368(98)00054-7.

40. Rong, M.Z.; Zhang, M.Q.; Liu, Y.; Yang, G.C.; Zeng, H.M. The Effect of Fiber Treatment on the Mechanical Properties of Unidirectional Sisal-Reinforced Epoxy Composites. Compos. Sci. Technol. 2001, 61, 1437- 
1447, https://doi.org/10.1016/S0266-3538(01)00046-X.

41. Godara, S.S. ScienceDirect Effect of Chemical Modification of Fiber Surface on Natural Fiber Composites : A Review. Mater. Today Proc. 2019, 18, 3428-3434, https://doi.org/10.1016/j.matpr.2019.07.270.

42. Kabir, M.M.; Wang, H.; Lau, K.T.; Cardona, F. Effects of Chemical Treatments on Hemp Fibre Structure. Appl. Surf. Sci. 2013, 276, 13-23, https://doi.org/10.1016/j.apsusc.2013.02.086.

43. Nishiyama, Y.; Okano, T. Morphological Changes of Ramie Fiber during Mercerization. J. Wood Sci. 1998, 44, 310-313, https://doi.org/10.1007/BF00581312.

44. Izani, M.A.N.; Paridah, M.T.; Anwar, U.M.K.; Nor, M.Y.M.; H'ng, P.S.. Effects of Fiber Treatment on Morphology, Tensile and Thermogravimetric Analysis of Oil Palm Empty Fruit Bunches Fibers. Comp. Part B: Eng. 2013, 45, 1251-1257, https://doi.org/10.1016/j.compositesb.2012.07.027.

45. Ridzuan, M.J.M.; Abdul Majid, M.S.; Afendi, M.; Aqmariah Kanafiah, S.N.; Zahri, J.M.; Gibson, A.G. Characterisation of Natural Cellulosic Fibre from Pennisetum Purpureum Stem as Potential Reinforcement of Polymer Composites. Mater. Des. 2016, 89, 839-847, https://doi.org/10.1016/j.matdes.2015.10.052.

46. Raia, R.Z.; Iwakiri, S. Effects of Alkali Treatment on Modification of the Pinus Fibers. Matéria 2021, 26, https://doi.org/10.1590/S1517-707620210001.1236.

47. Mbeche, S.M.; Omara, T. Effects of Alkali Treatment on the Mechanical and Thermal Properties of Sisal / Cattail Polyester Commingled Composites. PeerJ Mat. Sci. 2020, 2, https://doi.org/10.7717/peerj-matsci.5.

48. Faruk, O.; Bledzki, A.K.; Fink, H P.; Sain, M. Biocomposites Reinforced with Natural Fibers: 2000-2010. Prog. Polym. Sci. 2012, 37, 1552-1596, https://doi.org/10.1016/j.progpolymsci.2012.04.003.

49. Bisanda, E.T.N. Effect of Alkali Treatment on the Adhesion Characteristics of Sisal Fibres. Appl. Compos. Mater. 2000, 7, 331-339, https://doi.org/10.1023/A:1026586023129.

50. Ridzuan, M.J.M.; Majid, M.S.A.; Afendi, M.; Azduwin, K.; Kanafiah, S.N.A.; Dan-mallam, Y. The Effects of the Alkaline Treatment's Soaking Exposure on the Tensile Strength of Napier Fibre. Procedia Manuf. 2015, 2, 353-358, https://doi.org/10.1016/j.promfg.2015.07.062.

51. Sanjay, M.R.; Madhu, P.; Jawaid, M.; Senthamaraikannan, P.; Senthil, S.; Pradeep, S. Characterization and Properties of Natural Fiber Polymer Composites: A Comprehensive Review. J. Clean. Prod. 2018, 172, 566581, https://doi.org/10.1016/j.jclepro.2017.10.101.

52. Ku, H.; Wang, H.; Pattarachaiyakoop, N.; Trada, M. A Review on the Tensile Properties of Natural Fiber Reinforced Polymer Composites. Compos. Part B Eng. 2011, 42, 856-873, https://doi.org/10.1016/j.compositesb.2011.01.010.

53. Preet Singh, J.I.; Dhawan, V.; Singh, S.; Jangid, K. Study of Effect of Surface Treatment on Mechanical Properties of Natural Fiber Reinforced Composites. Mater. Today Proc. 2017, 4, 2793-2799, https://doi.org/10.1016/j.matpr.2017.02.158.

54. Li, X.; Tabil, L.G.; Panigrahi, S.; Crerar, W.J. The Influence of Fiber Content on Properties of Injection Molded Flax Fiber-HDPE Biocomposites. 2006. 